\title{
EXPERIMENTAL FLAME HEAT TRANSFER CORRELATIONS FOR A STEEL COLUMN ADJACENT TO AND SURROUNDED BY A POOL FIRE
}

\author{
Daisuke Kamikawa and Yuji Hasemi \\ Department of Architecture, Waseda University, Okubo 3-4-1, Shinjuku-ku, Tokyo, 169-8555, Japan \\ Takashi Wakamatsu
}

Kumagai-gumi Co. Technica ICenter, Onigakubo 1043, Tsukuba, Ibaraki, 300-2651, Japan

Koji Kagiya

National Institute for Land Infrastructure Management,Ministry of Land, Infrastructure and Transport, Tachihara 1, Tsukuba-City, Ibaraki, 302-0802, Japan

\begin{abstract}
Heat flux and temperature measurements were conducted on a square steel column adjacent to and surrounded by fire sources from the interest in the application to the structural fire safety design of metal structures. The tests on the adjacent fires demonstrate a description of the heat flux profile along the column surface as a single function of the height normalized by flame height for each column-fire distance and notable decrease of surface heat flux by the increase of the column-source distance. Surface temperature of the column in this configuration was found to be notably lower than the estimate from heat flux data based on the uniform heating assumption, which suggests the significance of the conductive heat loss to unheated surfaces of the column. The tests on the surrounding fires has resulted in heat flux profile weakly dependent on heat release rate and coincidence of the measured surface temperature and its estimate from heat flux due to rather even heat flux on all surfaces of the column.
\end{abstract}

Keywords: steel structure, unprotected structure, localized fire, heat flux, flame height

\section{INTRODUCTION}

Although steel structures are requested to be protected with thermal insulation in conventional fire safety design, there are many examples where building elements are submitted only to a localized heating during fire. If only a limited part of a structure is exposed to fire, its fire resistance may be significantly different from that obtained assuming uniform temperature distribution. It is believed that the main reason why only uniform heating was considered when analyzing behavior of structures in fire is that the only means of evaluations were standard fire resistance tests on single elements. If we consider such structures as atria, open car parks, railway stations, etc. in terms of fire safety design, types and location of the fire load is generally limited and specifiable. In such cases, any fire would be of a fuel-controlled type, and the fire and the effect of heating on structural members could remain 
localized. It may be assumed that the rise in temperature is smaller than in the event of all the members being subjected to heating by fire. When a metal structural member is heated only locally in a fire, temperature of the member will rapidly even out due to the accelerated heat conduction through the member itself. These effects have drawn attention of structural engineers, and numbers of large scale tests have been conducted to examine mechanical response of steel structures to natural fires ${ }^{1,2)}$. Also, the authors conducted heat flux and temperature measurements on a steel beam below an inert ceiling above a propane diffusion flame simulating a natural fire and confirmed the relaxation of temperature rise due to the "localized fire effect",3). Through comparison between the measured temperature against numerical calculations by using the heat flux correlation as the input, effectiveness of such numerical methods as Finite Element Method and Finite Difference Method as a tool for the fire safety assessment of such structures was also verified ${ }^{4,5}$.

However, a column should need more careful examination than a beam as a load-bearing element because buckling of a column may cause serious damage to the whole building while influence of the damage of a beam is essentially limited to the local floor slab supported by the beam. Also, column can be heated directly by any nearby burning object in the event of a fire, while the heating of a beam is significant only when the flame becomes large enough to reach the beam. Although considerable studies have been made on the flame heating of vertical building components, most of such works deal with wall fires ${ }^{6-9)}$ and there is virtually no heat flux measurement on columns near a flame. When a column is compared with a wall, large difference is anticipated in the flame heating since the entrainment across the column is believed to make the flame length shorter than a wall flame and also cool the column. These should generally make the flame heating of the surface weaker than the wall fire configuration.

In this research, measurements have been conducted using a model scale facility on flame length, flame heat transfer, and temperature field of a steel column exposed to a fire source. Two different experiment al configurations are considered; only one side of the square-sectional column being exposed to a square fire source and the column totally surrounded by a pool fire. The former configuration was chosen to represent the simplest and probably the most plausible geometrical condition of a localized fire and the another represents the "worst case" within the localized fire scenario. Following previous flame heat transfer measurements on walls, ceilings and beams, it has been attempted to correlate the vertical heat flux distribution along the column specimen against the height divided by the flame height. For this purpose, square porous propane burners were used as the fire source and heat release rate was controlled to produce diffusion flame s of different flame lengths. The primary aim of the study is to establish confidence in the "localized fire concept" with steel column and generate flame heat transfer correlations as the boundary conditions for the numerical calculation of the temperature field within the specimen. Temperature was monitored as a touchstone for the validation of such numerical codes. 


\section{EXPERIMENTAL DESCRIPTION}

\section{General}

Two $4.5 \mathrm{~mm}$ thick, $2.50 \mathrm{~m}$ tall and $0.15 \mathrm{~m}$ square steel columns were prepared as the specimen; one with a line of holes for the installation of $15 \mathrm{~mm}$ diameter Schmidt - Boelter heat flux gages $\left(150 \mathrm{~kW} / \mathrm{m}^{2}\right.$ full range) and the another with $0.20 \mathrm{~mm}$ diameter K-type thermocouples. The upper end of each column was semi-closed in order to prevent excessive pressure rise in the cavity of the column. Temperature was monitored on all the external surfaces of the specimen and in the cavity after the surface temperature of the specimen had reached nearly the steady state. Incident heat flux was measured at the interval of 2 seconds for 2 minutes for each heat release rate $\mathrm{Q}$, and we report its average. Flame was recorded with digital video, and the average of visible flame tips height for one minute sampled at the interval of 1 second will be reported. The heat flux and the temperature measurements were conducted independently to avoid intervention between the two measurements. Heat release rate was controlled by fuel supply rate to cover a wide range of flame height within the length of the column. The reported heat release rates are nominal ones calculated assuming the complete combustion. These experiments do not intend to simulate any specific building nor burning object, but the sectional dimension of the specimen is around $1 / 3$ of that of common steel component. Assuming the scaling by $1 / 3$, according to the Froude modeling, heat release rate in these experiments is believed to correspond to a fire source of the heat release rate $15.6\left(3^{5 / 2}\right)$ times larger than the test condition.

\section{Adjacent Fire Tests}

A $0.50 \mathrm{~m}$ square diffusion burner with propane as the fuel was used as the fire source(Figure 1). The burner surface was $450 \mathrm{~mm}$ above the floor of the laboratory. Heat release rate was controlled to produce a wide range of flame height within the length of the specimen. In order to investigate into the effectiveness of the isolation of the column from the fire source, burner- column distance, L, was changed between 0 and $250 \mathrm{~mm}$, i.e. within the range of $\mathrm{L} / \mathrm{D}=0-0.50$. Heat flux was monitored not only on the front surface of the specimen but also on the side surface by rotating the column by 90 degree because the flood of the flame had been observed during preliminary tests especially with low L/D ratio, and it was thought that the heating of the side surface is not ignorable. Table 1 is a summary of the experimental conditions. The reference flame height, $\mathrm{L}_{\mathrm{f}}^{*}$, was calculated by experimental flametips

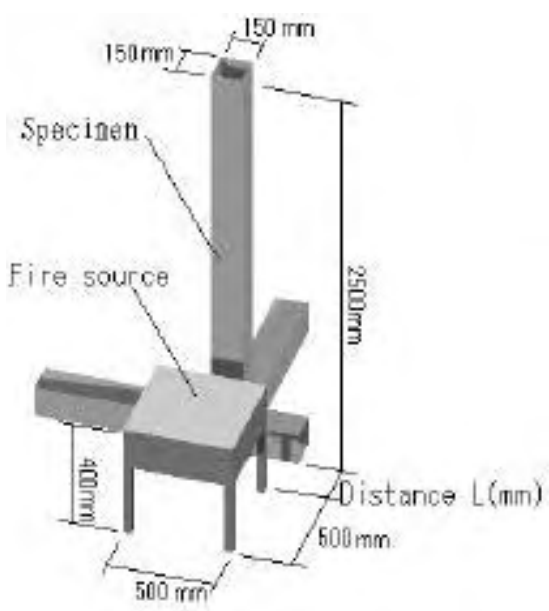

Figure 1 Experimental arrengement for Adjacent Fire Tests 
height formula, $\mathrm{L}_{\mathrm{f}}^{*}=3.5 \mathrm{Q} *{ }^{*} \mathrm{D}$, where $\mathrm{n}=2 / 3$ for $\mathrm{Q}^{*}<1.0$ and $\mathrm{n}=2 / 5$ for $\mathrm{Q}^{*}>1.0$.

Table 1Test Conditions, Adjacent Fires

\begin{tabular}{|l|l|l|l|}
\hline $\begin{array}{l}\text { Nominal Heat } \\
\text { Release Rate }(\mathrm{kW})\end{array}$ & $\mathrm{Q}^{*}(-)$ & $\begin{array}{l}\text { Calculat ed Unconfined } \\
\text { Flame Height, } \mathrm{L}_{*}^{*}(\mathrm{~m})\end{array}$ & $\begin{array}{l}\text { Column-Burner } \\
\text { Distance }(\mathrm{mm})\end{array}$ \\
\hline 52 & 0.26 & 0.72 & $0,25,50,125$ \\
\hline 105 & 0.53 & 1.15 & $0,25,50,125$ \\
\hline 157 & 0.79 & 1.51 & $0,25,50,125$ \\
\hline 210 & 1.06 & 1.79 & $0,25,50,125,250$ \\
\hline 255 & 1.29 & 1.94 & $0,25,50,125,250$ \\
\hline
\end{tabular}

\section{Surrounding Fire Tests}

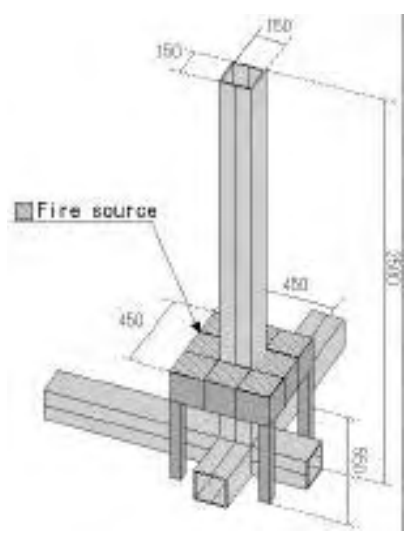

Figure 2 Experimental arrengement for Surrounding Fire Tests

Eight $0.15 \mathrm{~m}$ square porous burners were placed around the $0.15 \mathrm{~m}$ square column to make a $0.45 \mathrm{~m}$ square burner-column complex. Total heat release rate(nominal) was controlled within the range from 40.5 to $162 \mathrm{~kW}$ to reproduce the identical $\mathrm{Q}^{*}$ with the adjacent fire configuration. Table 2 is a summary of the experimental conditions.

Table 2Test Conditions, Surrounding Fires

\begin{tabular}{|l|l|l|l|}
\hline $\begin{array}{l}\text { Nominal Heat } \\
\text { Release Rate }(\mathrm{kW})\end{array}$ & & $\begin{array}{l}\text { Calculated Unconfined } \\
\text { Flame Height, } \mathrm{L}_{\mathrm{f}}^{*}(\mathrm{~m})\end{array}$ & $\begin{array}{l}\text { Measured Flame } \\
\text { Height, } \mathrm{L}_{\mathrm{f}}(\mathrm{m})\end{array}$ \\
\hline 40.5 & 0.26 & 0.65 & 0.68 \\
\hline 81 & 0.53 & 1.04 & 1.00 \\
\hline 121.5 & 0.79 & 1.36 & 1.19 \\
\hline 162 & 1.06 & 1.65 & 1.44 \\
\hline
\end{tabular}

\section{EXPERIMENTAL RESULT}

\section{Flame height}

Figure3 shows the relationship between $\mathrm{Q}^{*}$ and flame height divided by $\mathrm{D}$ for the both series of the experiments. The column-fire source distance and the difference of the configuration, whether the 
adjacent fire or the surrounding fire, do not seem to strongly affect on the flame height correlation.

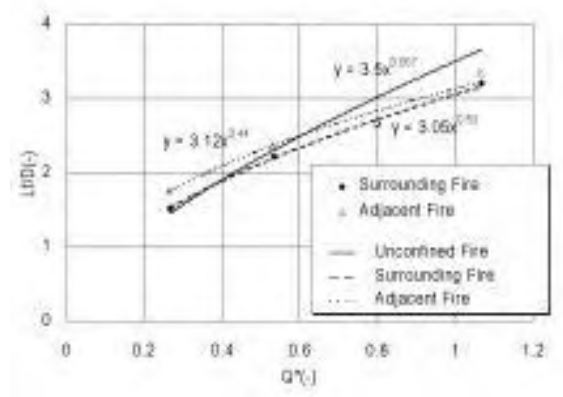

Figure 3 Relationshin between $O *$ and flame height divided bv D

Though the measured flame heights are generally close to that of unconfined flame tips height established in previous experiments ${ }^{10}$, the power dependence of $\mathrm{L}_{\mathrm{f}} / \mathrm{D}$ on $\mathrm{Q}^{*}$ of the current experiments is slightly weaker than that for unconfined flames. It is noteworthy that, at the adjacent fire configuration, if $\mathrm{Q}^{*}$ and L/D are sufficient ly small the flame divides into two summits, one creeping along the column and the another right above the center of the burner.

\section{Overall Localized Fire Effect}

Degree of the relaxation of the temperature rise of the specimen due to localized heating can be evaluated by comparing measured temperature of the specimen and its estimate calculated from the incident heat flux assuming one-dimensional thermal conduction. The estimate of surface temperature assuming uniform heating can be calculated from

$$
\mathrm{T}_{\mathrm{fu}}=(\mathrm{q} \text { "/ es })^{1 / 4}-273.16
$$

Figures 4(a) and (b) are a summary of the measured temperature on the front surface compared with that calculated from measured heat flux by equation (1) for the both configurations. Emissivity of the column surface, e, was assumed to be unity. For the adjacent fire configuration, the column- burner distance and heat release rate were chosen as $\mathrm{L} / \mathrm{D}=0$ and 0.10 , and $\mathrm{Q}=52 \mathrm{~kW}$ and $255 \mathrm{~kW}$.

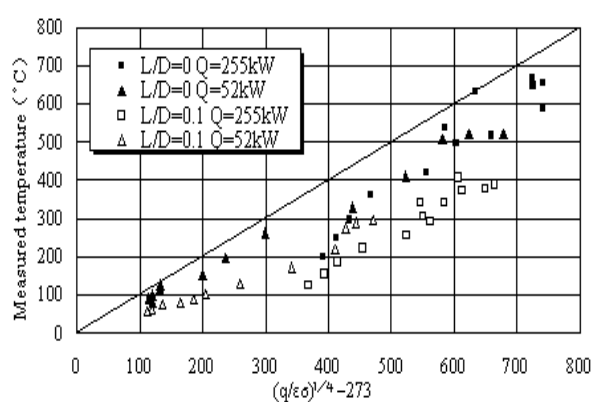

Figure 4 (a) Measured temperature and estimate based on uniform heating using heat flux data for Adjacent Fire Tests

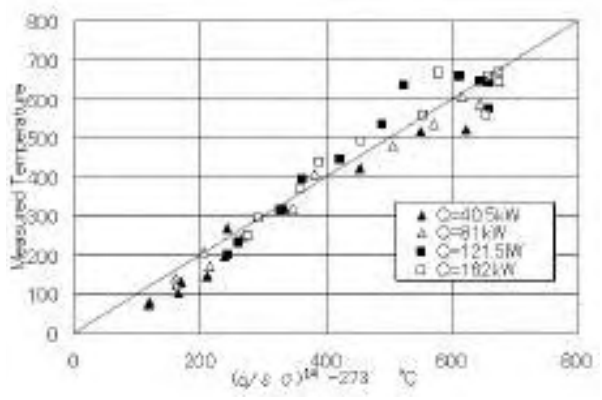

Figure 4 (b) Measured temperature and estimate based on uniform heating using heat flux data for Surrounding Fire Tests 
The "localized effect" in the structural fire safety design originates from two independent thermal processes in a metal structure, limitation of the heat flux level compared to fully developed fires and the accelerated heat loss from the directly heated area due to the high conductivity of the material. From the figure4(b), it is evident that, once a column is surrounded by fire, surface temperature of the column becomes very close to its estimate based on the uniform heating. This indicates that the high conductivity of steel no longer contributes to the relaxation of the heating of the column in the surrounding fire configuration.

In the adjacent fire configuration, systematic difference is seen between $\mathrm{L} / \mathrm{D}=0$ and $\mathrm{L} / \mathrm{D}=0.1$, clearly lower $T_{f} / T_{f u}$ ratio for $L / D=0.1\left(T_{f} / T_{f u}\right.$ ratio $\left.=0.3-0.6\right)$ than for for $L / D=0\left(T_{f} / T_{f u}=0.5-0.9\right)$ This significant improvement of the localized fire effect by separating the fire source only by $\mathrm{L} / \mathrm{D}=0.10$ is attributed to the limited direct flame exposure to the front surface when the fire source is separated from the column. This effect will be discussed in more detail in the later sections.

\section{Heat Flux}

(1)Vertical heat flux distribution on front surface of column, Adjacent fire configuration

Table 3 shows digital data of the heat. In previous flame heat transfer measurements on wall and ceiling, it was reported that flame heat flux to adjacent surface is expressed as a function of distance normalized by flame length ${ }^{3,6,8}$. Similarly, the heat flux data in the present experiments are summarized against the normalized height ( $\left(\mathrm{z} / \mathrm{L}_{\mathrm{f}}^{*}\right.$ ) for $\mathrm{L} / \mathrm{D}=0,0.10,0.25,0.50$ (Figures5-8). Only little difference was seen when $\mathrm{L}_{\mathrm{f}}^{*}$ was replaced by the measured flame height, $\mathrm{L}_{\mathrm{f}}$. We report the correlations against $\mathrm{z} / \mathrm{L}_{\mathrm{f}}^{*}$ because calculation using fire source information is much simpler on $\mathrm{L}_{\mathrm{f}}^{*}$ than on $\mathrm{L}_{\mathrm{f}}$.

Table 3 Vertical Heat Flux Distribution on a column for Adjacent Fire

\begin{tabular}{|c|c|c|c|c|c|c|}
\hline \multirow{2}{*}{\multicolumn{2}{|c|}{$\begin{array}{l}\text { HRR } Q(k W) \\
\text { Dimersionless HRR Q**(-) }\end{array}$}} & 52.5 & 105 & 157.5 & 210 & 255 \\
\hline & & 0.27 & 0.53 & 0.80 & 1.06 & 1.29 \\
\hline \multirow{13}{*}{$\begin{array}{l}\text { Heat Flux } \\
{\left[k \mathrm{~W} / \mathrm{m}^{2}\right]}\end{array}$} & Height $z=0.05(\mathrm{~m}$ & 36.7 & 39.9 & 44.9 & 47.0 & 42.9 \\
\hline & $\begin{array}{l}0.2 \\
\end{array}$ & 46.6 & 60.7 & 63.6 & 67.1 & 60.2 \\
\hline & 0.35 & 30.2 & 49.3 & 54.7 & 60.8 & 56.5 \\
\hline & 0.5 & 22.8 & 36.0 & 54.6 & 64.3 & 60.3 \\
\hline & 0.65 & 14.5 & 33.2 & 400 & 55.8 & 56.5 \\
\hline & 0.8 & 6.1 & 13.6 & 21.6 & 35.7 & 38.4 \\
\hline & 0.95 & 3.8 & 8.5 & 13.6 & 25.6 & 30.8 \\
\hline & 1.1 & 2.8 & 7.7 & 14.1 & 25.3 & 33.5 \\
\hline & 1.25 & 1.5 & 5.4 & 10.4 & 18.9 & 26.8 \\
\hline & 1.4 & 1.5 & 3.3 & $\begin{array}{ll}6.6 \\
\end{array}$ & 11.8 & 17.0 \\
\hline & 1.55 & 1.3 & 2.7 & 5.1 & 9.4 & 14.2 \\
\hline & 1.7 & 1.3 & 2.3 & 4.3 & 8.4 & 12.5 \\
\hline & 1.85 & 1.4 & 2.2 & 4.0 & 7.4 & 11.1 \\
\hline
\end{tabular}

(3) Heat Flux on Front Surface of Column (L/D=0.1)

\begin{tabular}{|c|c|c|c|c|c|c|}
\hline \multirow{2}{*}{\multicolumn{2}{|c|}{$\begin{array}{l}\text { HRR Q(kW) } \\
\text { Dimensionless HRRQ } *_{(-)}\end{array}$}} & 52.5 & 105 & 157.5 & 210 & 255 \\
\hline & & 0.27 & 0.53 & 0.80 & 1.06 & 1.29 \\
\hline \multirow{13}{*}{$\begin{array}{l}\text { Heat Flux } \\
{\left[\mathrm{k} W / \mathrm{m}^{2}\right]}\end{array}$} & Height $z=0.05(\mathrm{~m}$ & 14.9 & 22.3 & 278 & 27.7 & 25.7 \\
\hline & 0.2 & 17.4 & 28.4 & 37.5 & 36.9 & 34.9 \\
\hline & 0.35 & 13.6 & 24.1 & 33.8 & 35.7 & 33.9 \\
\hline & 0.5 & 12.4 & 25.3 & 39.5 & 43.5 & 43.9 \\
\hline & 0.65 & 8.1 & 18.8 & 32.0 & 39.2 & 41.1 \\
\hline & 0.8 & 4.6 & 11.8 & 19.5 & 29.8 & 30.7 \\
\hline & 0.95 & 3.0 & 8.5 & 15.0 & 24.4 & 26.1 \\
\hline & 1.1 & 2.5 & 7.0 & 13.8 & 24.1 & 27.7 \\
\hline & 1.25 & 2.1 & 5.4 & 10.5 & 19.1 & 22.9 \\
\hline & 1.4 & 1.6 & 3.8 & 7.6 & 130 & 15.9 \\
\hline & 1.55 & 1.3 & 2.9 & 5.1 & 9.5 & 12.7 \\
\hline & 1.7 & 1.3 & 2.7 & 4.9 & 8.6 & 11.2 \\
\hline & 1.85 & 1.2 & 2.3 & 4.1 & 7.4 & 9.6 \\
\hline
\end{tabular}

(2) Heat Flux on Side Surface of Column ( $L / D=0)$

\begin{tabular}{|c|c|c|c|c|c|c|}
\hline \multirow{2}{*}{\multicolumn{2}{|c|}{\begin{tabular}{|l} 
HRR Q(kW) \\
Dimensionless HRR Q**(-)
\end{tabular}}} & 52.5 & 105 & 157.5 & 210 & 255 \\
\hline & & 0.27 & 0.53 & 0.80 & 1.06 & 1.29 \\
\hline \multirow{13}{*}{$\begin{array}{l}\text { Heat Flux } \\
{\left[\mathrm{kW} / \mathrm{m}^{2}\right]}\end{array}$} & Height $z=0.05(\mathrm{~m})$ & 0.5 & 0.9 & 1.7 & 2.4 & 25 \\
\hline & 0.2 & 0.4 & 0.8 & 1.6 & 2.4 & 2 \\
\hline & 0.35 & 1.3 & 1.8 & 2.8 & 3.7 & 3. \\
\hline & 0.5 & 2.2 & 5.6 & 5.3 & 7.2 & \\
\hline & 0.65 & 2.5 & 6.8 & 8.2 & 12.2 & 20. \\
\hline & 0.8 & 1.6 & 3.9 & 4.9 & 10.4 & 16. \\
\hline & 0.95 & 1.0 & 2.9 & 3.6 & 9.2 & 14. \\
\hline & 1.1 & 1.0 & 2.9 & 3.2 & 8.6 & 14. \\
\hline & 1.25 & 1.0 & 2.4 & 3.1 & 7.7 & 11. \\
\hline & 1.4 & 0.8 & 1.5 & 2.4 & 5.4 & \\
\hline & 1.55 & 0.6 & 1.2 & 2.1 & 3.9 & \\
\hline & 1.7 & 0.7 & 1.3 & 2.0 & 3.3 & \\
\hline & 1.85 & 0.7 & 1.7 & 2.2 & 2.9 & \\
\hline
\end{tabular}

(4) Heat Flux on Front Surface of Column ( $L / D=0.25$ )

\begin{tabular}{|c|c|c|c|c|c|c|}
\hline & & & \multirow{2}{*}{$\begin{array}{r}157.5 \\
0.80 \\
176\end{array}$} & \multirow{2}{*}{$\begin{array}{l}210 \\
1.06 \\
\end{array}$} & \multirow{2}{*}{$\begin{array}{r}255 \\
1.29 \\
100\end{array}$} \\
\hline & & & & & & \\
\hline \multirow{13}{*}{$\begin{array}{l}\text { Heat Flux } \\
{\left[\mathrm{k} \mathrm{W} / \mathrm{m}^{2}\right]}\end{array}$} & \begin{tabular}{|l} 
HRR Q(kW) \\
Dimensionless HRR Q**(-) \\
Heat Flux height $z=0$ o5(m)
\end{tabular} & $\begin{array}{r}52.5 \\
0.27 \\
8.4\end{array}$ & \begin{tabular}{|r|r|}
5 & 105 \\
7 & 0.53 \\
4 & 14.4 \\
\end{tabular} & & & \\
\hline & $\begin{array}{l}0.2 \\
\end{array}$ & 9.8 & 183 & 23.4 & 25.4 & 25.4 \\
\hline & 0.35 & 7.4 & 15.5 & 21.5 & 240 & 24.3 \\
\hline & 0.5 & 6.8 & 16.4 & 24.6 & 30.1 & 29.7 \\
\hline & 0.65 & 4.8 & 12.1 & 20.9 & 27.7 & 28.4 \\
\hline & 0.8 & 2.8 & 7.6 & 14.5 & 207 & 23.7 \\
\hline & 0.95 & 1.9 & 4.9 & 11.1 & 18.9 & 28.5 \\
\hline & 1.1 & 1.5 & 3.8 & 8.9 & 17.0 & 24.6 \\
\hline & 1.25 & 1.4 & 3.5 & 8.4 & 14.9 & 21.9 \\
\hline & 1.4 & 0.9 & 2.1 & 5.6 & 10.1 & 15.1 \\
\hline & 1.55 & 0.9 & 1.7 & 3.5 & 6.8 & 12.0 \\
\hline & 1.7 & 0.9 & 1.6 & 3.1 & 5.8 & 10.9 \\
\hline & 1.85 & 1.0 & 1.5 & 2.8 & 4.7 & 9.2 \\
\hline
\end{tabular}




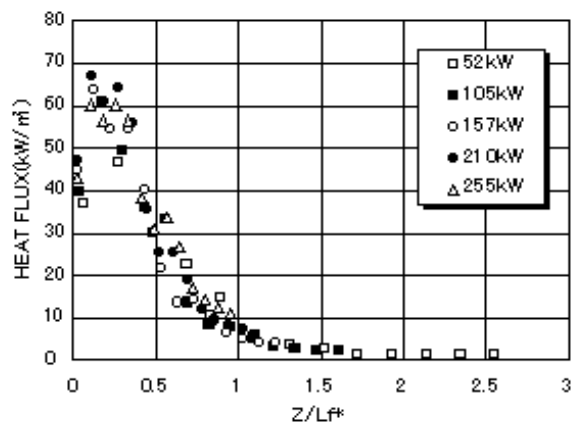

Figure5 Vertical heat flux distribution on front surface $(\mathrm{L} / \mathrm{D}=0)$

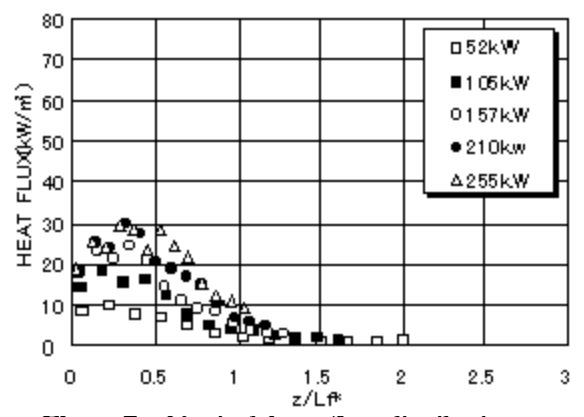

Figure7 Vertical heat flux distribution on front surface $(\mathrm{L} / \mathrm{D}=0.25)$

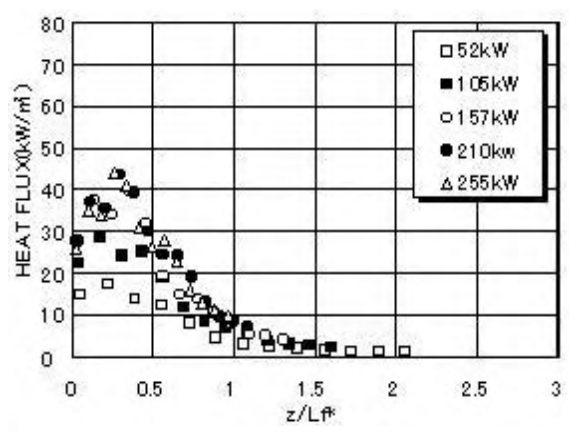

Figure6 Vertical heat flux distribution on front surface $(\mathrm{L} / \mathrm{D}=0.10)$

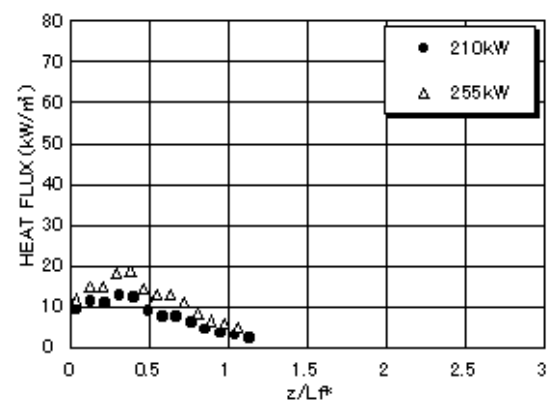

Figure8 Vertical heat flux distribution on front surface $(\mathrm{L} / \mathrm{D}=0.50)$

In each Figure, there is one significant peak in the range of $0.2<\left(\mathrm{z} / \mathrm{L}_{\mathrm{f}}^{*}\right)<0.4$. In comparison with flame heat flux distribution on the wall surface ${ }^{6,8)}$, there is a marked decrease of heat flux downward toward the column base $\left(\mathrm{z} / \mathrm{L}_{\mathrm{f}} *<0.2\right)$. This is attributed to the air entrainment to the flame passing by the column base and resulting cooling of the column in the present configuration, whereas there is virtually no entrainment from the wall side in a wall fire configuration. Obviously, heat flux decreases significantly as $\mathrm{L} / \mathrm{D}$ increases. Within the flame $\left(0<\mathrm{z} / \mathrm{L}^{*}<1\right)$, even a small distance between fire source and column, $\mathrm{L} / \mathrm{D}=0.1$, lowers heat flux almost by half. Also it seen for $\mathrm{L} / \mathrm{D}<0.5$ that the bigger $\mathrm{L} / \mathrm{D}$ becomes, the higher $\left(\mathrm{z} / \mathrm{L}_{f}^{*}\right)$ where heat flux reaches the peak becomes.

Also it is noteworthy that, except for $\mathrm{L} / \mathrm{D}=0$, there is a systematic difference in the heat flux profile according to heat release rate. However, heat flux is represented as almost a single function of $\mathrm{z} / \mathrm{L}_{\mathrm{f}}$ for $\mathrm{L} / \mathrm{D}=0$ except for low heat release rate, say $\mathrm{Q}=52 \mathrm{~kW}$. This single dependence of heat flux on $\mathrm{z} / \mathrm{L}_{\mathrm{f}}$ is similar to the flame hear transfer correlations in wall fire and ceiling fire, and its independence on heat release rate is attributed to the weak dependence of flame radiation on the heat release rate. The heat flux in the solid flame for $\mathrm{Q}=52 \mathrm{~kW}$ slightly weaker than others is probably because $\mathrm{Q} *$ of this condition is very low and the flame thickness is considerably thin. On the other hand, once the fire source is apart from the column surface, remote radiation from the flame becomes dominant in the surface heating and is controlled by the configuration factor between the flame and the heated surface. The systematic 
increase of heat flux with the source intensity for $L / D>0$ is believed to simply reflect the increase of the configuration factor of the flame with respect to heat release rate. The rather strong flame heat flux within the solid flame for $\mathrm{L} / \mathrm{D}=0$ irrespective of heat release rate implies that even a small fire source could cause significant flame heating once it directly attaches to a building component. Figures 5-8 suggest significant effectiveness of the geometrical isolation of an unprotected column from any combustible objects.

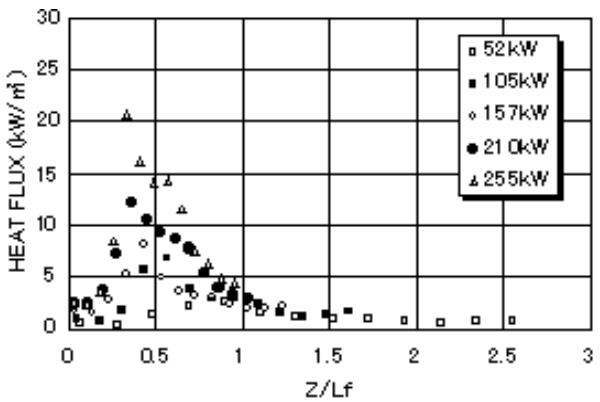

Figure9 Vertical heat flux distribution on side surface $(\mathrm{L} / \mathrm{D}=0)$

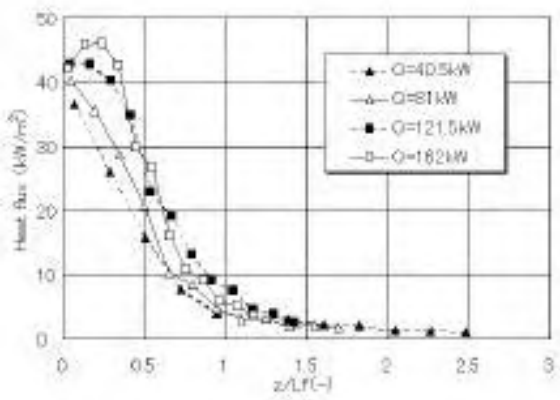

Figure10 Vertical heat flux distribution on front surface for sorrounding fire $(\mathrm{L} / \mathrm{D}=0)$

(2)Vertical heat flux distribution on side surface of column, Adjacent fire configuration

The heat flux distributions on the side surface for $\mathrm{L} / \mathrm{D}=0$ are summarized in Table 3(2) and Figure 9. Unlike the heat flux to the front surface (Figure 5), there is systematic increase of heat flux with respect toheat release rate. Heat flux to the side surface becomes significantly weaker once the burner is separated from the column. The maximum heat flux increases as the heat release rate becomes larger, and for Q not less than $210 \mathrm{~kW}$, it exceeds $10 \mathrm{~kW} / \mathrm{m}^{2}$. Such strong heating of the sides not directly adjacent to the fire source is believed to weaken the heat loss from the front surface. The maximum heat flux appears at $\mathrm{z} / \mathrm{L}_{\mathrm{f}}^{*}=0.4$. This height is higher than that on the front surface ( Figure 5 ). This is attributed to the horizontal extension of the flooded flame with increase of heat release rate.

\section{(3)Vertical heat flux distribution, Surrounding fire configuration}

The vertical heat flux distributions along the surface of the column surrounded by a pool fire are summarized in Figure 10. Because of the lack of air-cooling of the column by entrainment, there is no significant downward decrease of heat flux in the solid flame. The flux profile for $\mathrm{z} / \mathrm{L}_{\mathrm{f}}^{*}>0.5$ is close to that for the adjacent fire configuration, however the heat flux at lower $\mathrm{z} / \mathrm{L}_{\mathrm{f}} *$ is notably weaker than for the adjacent fire configuration and is weakly dependent on heat release rate. Since each column surface is exposed to only a half of the whole flame, the flame thickness effective for the heating of each surface is considerably thinner than in the adjacent configuration. The weak and Q-dependent heat flux within the flame in the surrounding fire configuration is attributed to the thinner "effective" flame thickness than in the adjacent fire configuration. From this estimation, it is expected that, for lager fire source intensity, heat flux in the solid flame could become still lager than the present report. 


\section{Temperature}

(1)Adjacent fire configuration

Figures 11-14 demonstrate example of vertical temperat ure distributions on the front surface, the side surface, the back surface and the cavity of the. The temperatures calculated using the measured heat flux by equation(1) assuming steady uniform heating are also shown in each Figure for the examination of the conductive effects .Temperature is the highest on the front surface, and temperatures in the cavity and on the side surface show almost similar distribution expect for $\mathrm{L} / \mathrm{D}=0, \mathrm{Q}=255 \mathrm{~kW}$. The temperature difference in the vertical direction is the most pronounced on the front surface, e.g. the difference between the highest temperature and the temperature just above the flame tips for $\mathrm{L} / \mathrm{D}=0$ and $\mathrm{Q}=255 \mathrm{~kW}$ being around $500 \mathrm{~K}$. Notable temperature difference can be seen also between the front surface and other surfaces especially in the solid flame, e.g. around $400 \mathrm{~K}$ for $\mathrm{L} / \mathrm{D}=0$ and $\mathrm{Q}=255 \mathrm{~kW}$.

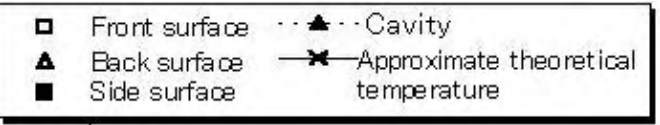

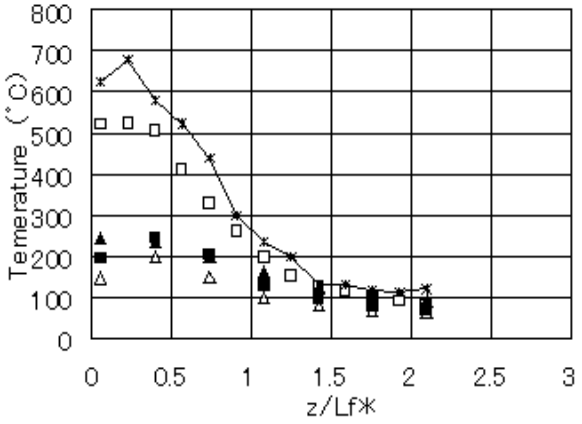

Figure11 Vertical temperature distribution on side surface $(\mathrm{L} / \mathrm{D}=0, \mathrm{Q}=52 \mathrm{~kW})$

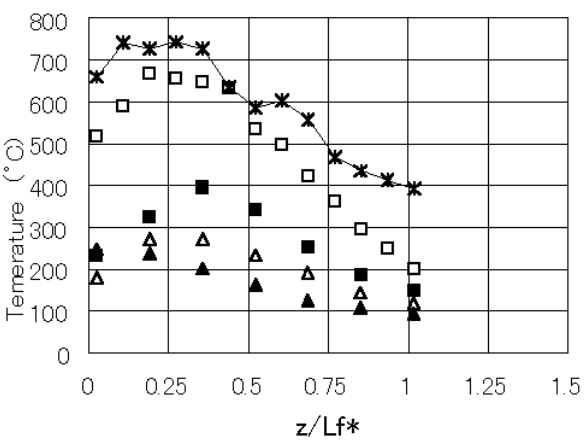

Figure13 Vertical temperature distribution on side surface $(\mathrm{L} / \mathrm{D}=0, \mathrm{Q}=255 \mathrm{~kW})$

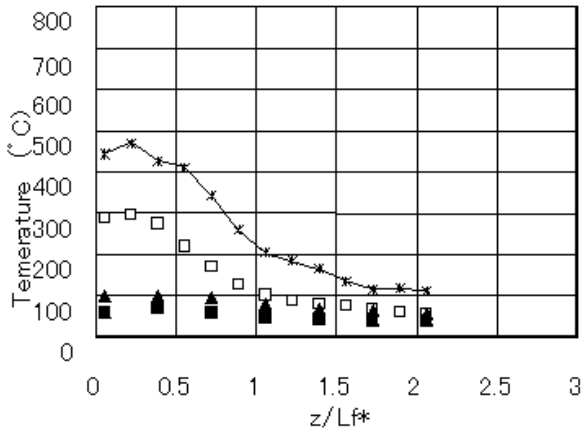

Figure12 Vertical temperature distribution on side surface $(\mathrm{L} / \mathrm{D}=0.10, \mathrm{Q}=52 \mathrm{~kW})$

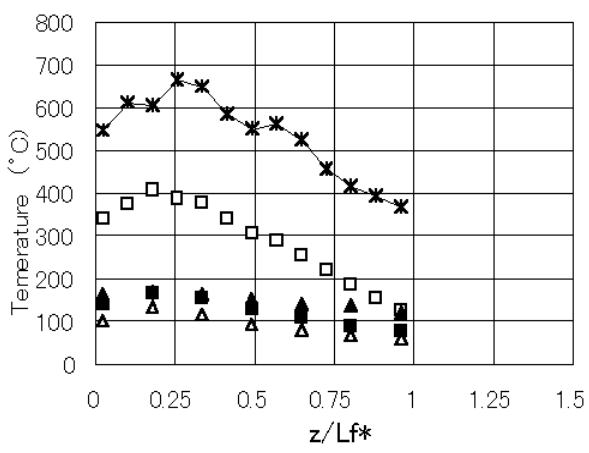

Figure14 Vertical temperature distribution on side surface $(\mathrm{L} / \mathrm{D}=0.10, \mathrm{Q}=255 \mathrm{~kW})$ 
This strong multidimensional temperature distribution is different from a beam above a localized fire where only the axial temperature profile is pronounced. This suggests importance of the careful modeling of conductive heat loss for a column while even a simple one-dimensional Finite Difference Calculation was found to be effective for the prediction of the temperature field of a beam above a localized fire ${ }^{5}$. The maximum temperature on the front surface appears in the solid flame range $\left(\mathrm{z} / \mathrm{L}_{\mathrm{f}} *<0.5\right)$. For $\mathrm{L} / \mathrm{D}=0, \mathrm{Q}=255 \mathrm{~kW}$, temperature rise on the side and the back surface is far more pronounced than for other conditions. This is attributed to the heating by the flooding flame toward the column sides when fire source is adjacent to the column, as shown in Figure 9. The front surface temperature in solid flame range $\left(\mathrm{z} / \mathrm{L}_{\mathrm{f}} *=0.5\right)$ for $\mathrm{L} / \mathrm{D}=0, \mathrm{Q}=255 \mathrm{~kW}$ (Figure 13), is also remarkably higher than that for $\mathrm{L} / \mathrm{D}=0, \mathrm{Q}=52 \mathrm{~kW}$ (Figure 11). A reason for this is the suppression of the heat loss due to the strong heating to the side surfaces by the increase of the source intensity. Surface temperature was found to be extremely sensitive to the column-burner distance as seen in the difference between Figure13, $\mathrm{L} / \mathrm{D}=0$ and Figure14, $\mathrm{L} / \mathrm{D}=0.10$. The front surface temperature within the solid flame, i.e. $\mathrm{z} / \mathrm{L}_{\mathrm{f}}^{*}<0.5$, for $\mathrm{L} / \mathrm{D}=0$ is within the range where degradation of the mechanical properties of steel should be considered. The front surface temperature for $\mathrm{L} / \mathrm{D}=0.10$ demonstrate considerable relaxation of the temperature rise in the solid flame.

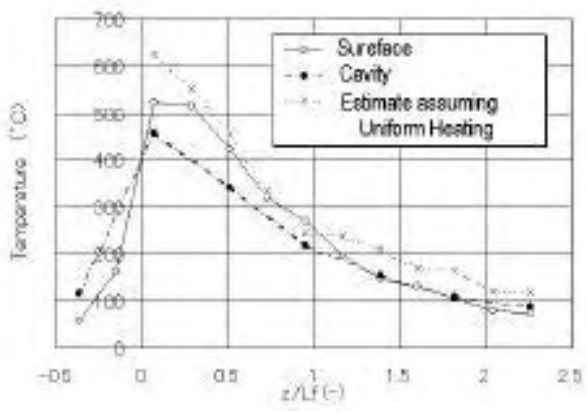

Figure 15 Vertical temperature distribution on side surface for surrounding fire $(\mathrm{Q}=40.5 \mathrm{~kW})$

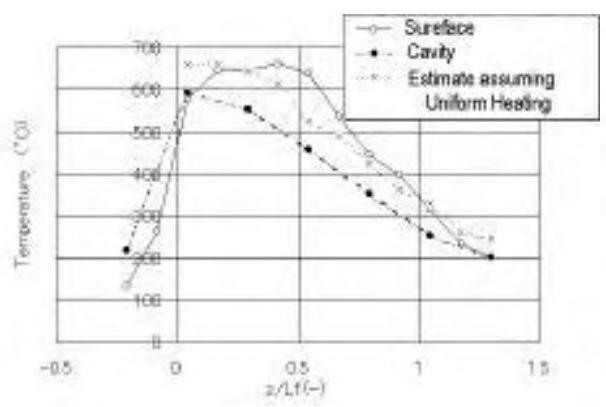

Figure 17 Vertical temperature distribution on side surface for surrounding fire $(\mathrm{Q}=121.5 \mathrm{~kW})$

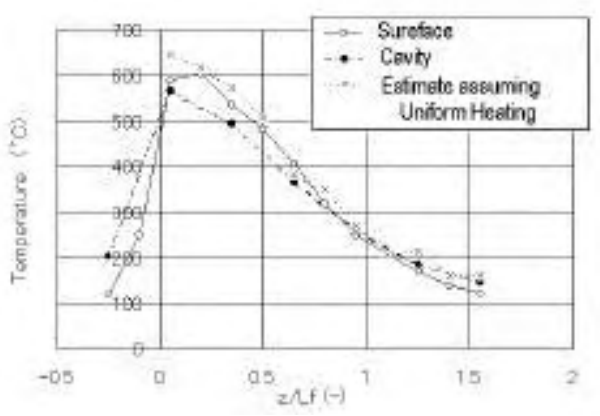

Figure 16 Vertical temperature distribution on side surface for surrounding fire $(\mathrm{Q}=81 \mathrm{~kW})$

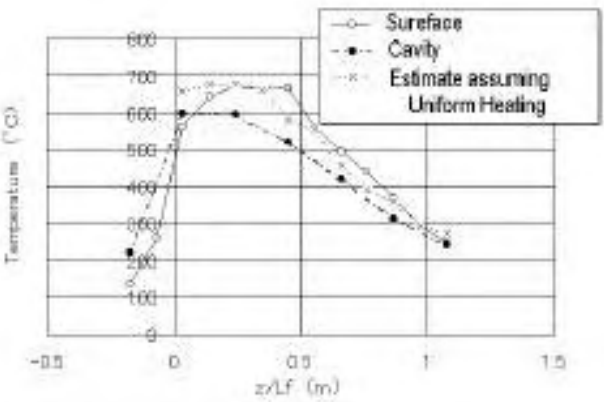

Figure 18 Vertical temperature distribution on side surface for surrounding fire ( $\mathrm{Q}=162 \mathrm{~kW})$ 
(2)Surrounding fire configuration

Vertical temperature distribution for each fire source intensity is summarized against $\mathrm{z} / \mathrm{L}_{\mathrm{f}}$ in Figure 15 18. The surface temperature of the column is generally close to the calculation using the heat flux data assuming steady uniform heating. Temperature within the flame, $\mathrm{z} / \mathrm{L}_{1}<1.0$ is generally higher than $300^{\circ} \mathrm{C}$, and the maximum temperature generally reaches the range where degradation of the mechanical properties of steel should be considered.

\section{CONCLUSIONS}

Heat flux and temperature distributions along a square column adjacent to and surrounded by a pool fire have been measured. From the results of the experiment, following conclusions can be drawn.

(1) The "localized fire" concept does not seem to apply to a column which can be surrounded by fire.

(2) The "localized fire effect" is confirmed for the adjacent fire configuration. In the present tests, the measured temperature rise is found to be $30-90 \%$ of its estimate assuming the uniform heating.

(3) Surface heat flux profile in the adjacent fire configuration is represented as a function of height normalized by flame height. The heat flax within the solid flame is affected by the air-cooling due to the entrainment.

(4) Separation of fire source from the column is significantly effective for the relaxation of the heating of the column in an adjacent fire configuration.

(5) Considerably large temperature gradient occurs in the vertical and horizontal direction in an adjacent fire configuration. In the experimental condition of $\mathrm{L} / \mathrm{D}=0$, temperature rises to over $500^{\circ} \mathrm{C}$ at $\mathrm{Q}=52 \mathrm{~kW}$ and about $700^{\circ} \mathrm{C}$ at $\mathrm{Q}=255 \mathrm{~kW}$. Numerical Prediction of the thermal response of a column should need a three-dimensional treatment, e.g. by Finite Element Method.

\section{ACKNOWLEDGMENTS}

This study has been carried out by the support of the JSPS Science Fund Grant 11555154 . The authors would like to acknowledge cooperation of Mr. Masatoshi Nakamura, graduate student of Waseda University, and Mr. Masashi Yoshida of National Institute for Land and Infrastructure Management during the experiments.

\section{TERMINOLOGY}

$\mathrm{C}_{\mathrm{p}} \quad$ :specific heat of air $[\mathrm{kJ} / \mathrm{kgK}]$

D : characteristic fuel size ( the length of side of the square burner in this paper) [m]

$\mathrm{L}$ : horizontal distance between fire source and member subject [m]

$\mathrm{L}_{f}$ : measured flame height $[\mathrm{m}]$

$\mathrm{L}_{f}^{*}$ : height of flame tips from unconfined flame calculated by semi-empirical formula [m]

$\mathrm{T}_{\mathrm{f}}$ : measured temperature on column surface $\left[{ }^{\circ} \mathrm{C}\right]$

$\mathrm{T}_{\mathrm{fu}}$ : calculated surface temperature assuming uniform and steady heating $\left[{ }^{\circ} \mathrm{C}\right]$

$\mathrm{T}_{\mathrm{o}}$ : ambient temperature $[\mathrm{K}]$

$\mathrm{Q}$ : heat release rate $[\mathrm{kW}]$

$\mathrm{Q}^{*}$ : dimensionless heat generation rate $\left(=\mathrm{Q} / \mathrm{C}_{\mathrm{p}} \mathrm{T}_{\mathrm{o}} \mathrm{g}^{1 / 2} \mathrm{D}^{5 / 2}\right) \quad[-]$ 
g : gravitational acceleration $(=9.8) \quad\left[\mathrm{m} / \mathrm{s}^{2}\right]$

q" : heat flux $\left[\mathrm{kW} / \mathrm{m}^{2}\right]$

$\mathrm{z}$ : height of measurement point $[\mathrm{m}]$

e : emissivity

$\mathrm{s} \quad$ : Stefan-Boltzman Constant $\left(=5.67 \times 10^{-11}\right)\left[\mathrm{kW} / \mathrm{s}^{2} \mathrm{~K}^{4}\right]$

? : density of ambient air $\left[\mathrm{kg} / \mathrm{m}^{3}\right]$

\section{REFERENCES}

1) Y. Sakumoto(1994). New Materials and New Methods for Fire Resistant Steel-frame Construction, Shokokusha Publishers(in Japanese).

2) D. Dhima, D. Joyux, J. Kruppa(1999). Fire Safety Engineering - Numerical Assessment of the Mechanical Behavior of a Steel Structure Exposed to a Natural Fire, Proceedings of the Sixth International Symposium on Fire Safety Science, 903-914.

3) Takashi Wakamatsu, Y Hasemi, Y. Yokobayashi and A.V. Pchelintsev(1996). Experimental Study on the Heating Mechanism of a Steel Beam under Ceiling Exposed to a Localized Fire, Proceedings of Interflam '96 Conference, 509-518.

4) A. V. Pchelintev, Y. Hasemi, Takasi Wakamatsu, Y. Yokobayashi(1997). Experimental and Numerical Study on the Behavior of a Steel Beam under Ceiling Exposed to a Localized Fire, Proceedings of the Fifth International Symposium on Fire Safety Science, 1153-1164.

5) Takashi Wakamatsu, and Y. Hasemi(1998) Heating Mechanism of Building Components Exposed to a Localized Fire- FDM Thermal and Structural Analysis of a Steel Beam under Ceiling, Proceedings of the Third Asia-Oceania Symposium on Fire Science and Technology, 335-346.

6) Y. Hasemi(1985) Thermal Modeling of Upward Wall Flame Spread, Proceedings of the First International Symposium on Fire Safety Sceince, 87-96.

7) M. M. Delichatsios, P. Wu, G. D. Loughheed, G. P. Grampton, C. Qian, H. Ishida, K. Saito(1994). Effect of External Radiant Heat Flux on Upward Fire Spread: Measurements on Plywood and Numerical Predictions, Proceedings of the Fourth International Symposium on Fire Safety Science, 421-432.

8) G. Back, C. Beyler, P. Dinenno and P. Taten(1994) Wall Incident Heat Flux Distributions Resulting from an Adjacent Fire, Proceedings of the Fourth International Symposium on Fire Safety Science, 241-252.

9) M. Foley and D. D. Drysdale(1995). Heat Transfer from Flames between Vertical Parallel Walls, Fire Safety Journal, Vol.24, No.1, 53-73

10) B. Cetegen, E. E. Zukoski, T. Kubota(1982) Entrainment and Flame Geometry of Fire Plumes, NBS-GCR-82-402. 